\title{
Effect of Estrogen upon the Juxtaglomerular Apparatus and the Renin-Angiotensin System in Rats
}

\author{
Kazuoki Kondo, Jiro Misumi, Ryuichi Nakamura, Ikuo \\ SaIto and Takao Saruta \\ Department of Internal Medicine, University of Keio School of \\ Medicine, Tokyo 160
}

\begin{abstract}
Kondo, K., Misumi, J., Nakamura, R., Sarto, I. and Saruta, T. Effect of Estrogen upon the Juxtaglomerular Apparatus and the Renin-Angiotensin System in Rats. Tohoku J. exp. Med., 1978, 126 (3), 267-272_-Administration of $1.5 \mathrm{mg} / \mathrm{kg}$ of estriol intramuscularly and $15 \mathrm{mg} / \mathrm{kg}$ of stilbestrol disulfate intraperitoneally daily for 15 days caused an increase in plasma renin substrate (PRS), accompanied by an increase in plasma renin activity (PRA) and a slight decrease in plasma renin concentration (PRC). Contrary to the slight suppres. sion of PRC, juxtaglomerular granulation index (JGI) was significantly increased in rats treated by estrogen. In the rats which developed hypertension by estrogen, PRA, PRC and JGI were a little higher than those in the rats which remained normotensive after the same estrogon treatment, but these differences were not statistically significant. Therefore, it seems rather difficult to attribute the development of estrogen hypertension only to the quantitative changes in the renin-angiotensin system. - estrogen; hypertension; renin-angiotensin system; juxtaglomerular apparatus.
\end{abstract}

Numerous clinical reports have suggested that administration of oral contraceptives leads to the development of hypertension in man (Laragh et al. 1967; Skinner et al. 1969; Saruta et al. 1970), and we have reported that high doses of estrogen can induce hypertension in rats (Saruta et al. 1975). The mechanism of action of estrogen in the development of hypertension is, however, still controversial. Since the first report about the effect of estrogen upon renin substrate by Helmer and Griffith (1952), a number of studies have suggested that remarkable changes in the renin-angiotensin system are induced by estrogen (Newton et al. 1968; Nasjletti et al. 1971; Menard and Catt 1973; Saruta et al. 1975; McDonald et al. 1977). Despite these studies it is still questionable whether changes of the reninangiotensin system are related to the development of estrogen hypertension or not.

In this study, the effect of estrogen upon the juxtaglomerular apparatus (JGA) was studied with measurement of plasma renin substrate, activity and concentration in the rats.

Received for publication, April 6, 1978.

Correspond to Takao Saruta, M.D., Department of Internal Medicine, Endocrine Section, University of Keio School of Medicine, 35, Shinanomachi, Shinjuku-ku, Tokyo 160, Japan. 


\section{Materials and Methods}

Male Wistar rats weighing $135-150 \mathrm{~g}$ were used for this study. 24 rats received one daily injection of $1.5 \mathrm{mg} / \mathrm{kg}$ of estriol intramuscularly and $15 \mathrm{mg} / \mathrm{kg}$ of stilbestrol disulfate intraperitoneally. The control group consisting of 7 rats received the same volume of distilled water. Systolic blood pressure of all animals was checked at intervals of five days. Blood pressure was measured with the modified tail-water plethysmographic method (Okamoto and Aoki 1963), and three readings for each rat were averaged.

After fifteen days, 7 rats which became hypertensive (the increase of blood pressure was more than $40 \mathrm{mmHg}$ ), 7 rats which remained normotensive (the change of blood pressure was less than $15 \mathrm{mmHg}$ ) and 7 control rats were sacrificed by decapitation. Blood was taken for renin assay and kidneys were removed to observe the JGA.

Plasma renin substrate (PRS), plasma renin concentration (PRC) and plasma renin activity (PRA) were determined by the method of Skinner (1967). The standard rat renin for the measurement of PRS was prepared by the method of Lever et al. (1964). A uniform renin substrate for the measurement of PRC was prepared from the plasma of rats obtained $24 \mathrm{hr}$ after nephrectomy.

Renal tissues were fixed in Bouin solution and embedded in epoxy resin by the method of Luft (1961). The blocks were cut with the ultramicrotome in $0.5-1.0 \mu \mathrm{m}$ thick sections. After the epoxy resin was removed by the method of Mayor et al. (1961), the sections were stained with the method of Bowie (1935-36). We evaluated the state of the JGA by estimating the degree of granularity of the JGA as juxtaglomerular granulation index (JGI) according to the method of Hartroft and Hartroft (1961).

Results were expressed as mean \pm s.D. For statistical analysis, an unpaired Student's $t$-test was employed.

\section{Results}

As a group, a significant increase of systolic blood pressure was observed in the estrogen treated group (from $109 \pm 7 \mathrm{mmHg}$ to $139 \pm 15 \mathrm{mmHg}, p<0.01$ ). Of estrogen treated 24 rats, however, 7 rats remained normotensive (the change of blood pressure was less than $15 \mathrm{mmHg}$ ), 7 rats developed definite hypertension (the increase of blood pressure was more than $40 \mathrm{mmHg}$ ), and the change of blood pressure of remaining 10 rats was between these two groups.

The results of JGI, PRS, PRA, PRC and the change in blood pressure in estrogen treated normotensive, estrogen treated hypertensive and control rats are given in Table 1 and Fig. 1.

The levels of PRS and PRA in the estrogen treated group were significantly

TABLE 1. Effect of estrogen upon blood pressure, plasma renin substrate, plasma renin activity, plasma renin concentration, and juxtaglomerular granulation index in rats (mean \pm s.D.)

\begin{tabular}{|c|c|c|c|c|c|c|c|}
\hline & \multirow{2}{*}{$\begin{array}{c}\text { Number } \\
\text { of } \\
\text { animals }\end{array}$} & \multicolumn{2}{|c|}{$\begin{array}{l}\text { Blood pressure } \\
(\mathrm{mmHg})\end{array}$} & \multirow{2}{*}{$\begin{array}{c}\text { PRS } \\
(\mathrm{ng} / \mathrm{ml})\end{array}$} & \multirow{2}{*}{$\begin{array}{c}\text { PRA } \\
(\mathrm{ng} / \mathrm{ml} / \mathrm{hr})\end{array}$} & \multirow{2}{*}{$\begin{array}{c}\text { PRC } \\
(\mathrm{U} / \mathrm{ml})\end{array}$} & \multirow{2}{*}{ JGI } \\
\hline & & Before & After & & & & \\
\hline $\begin{array}{l}\text { Control } \\
\text { Estrogen }\end{array}$ & 7 & $108 \pm 11$ & $111 \pm 11$ & $484 \pm 114$ & $4.9 \pm 1.3$ & $13.2 \pm 3.2$ & $16.4 \pm 4.5$ \\
\hline Normotensive & 7 & $110 \pm 6$ & $117 \pm 7$ & $1014 \pm 146^{*}$ & $10.0 \pm 0.4^{*}$ & $10.4 \pm 1.4^{\dagger}$ & $25.3 \pm 5.7^{*}$ \\
\hline Hypertensive & 7 & $108 \pm 9$ & $161 \pm 12$ & $1040 \pm 102^{*}$ & $11.1 \pm 1.1^{*}$ & $11.7 \pm 2.0$ & $31.3 \pm 8.7^{*}$ \\
\hline
\end{tabular}

* Different from control $p<0.01$. $\dagger$ Different from control $p<0.05$. 

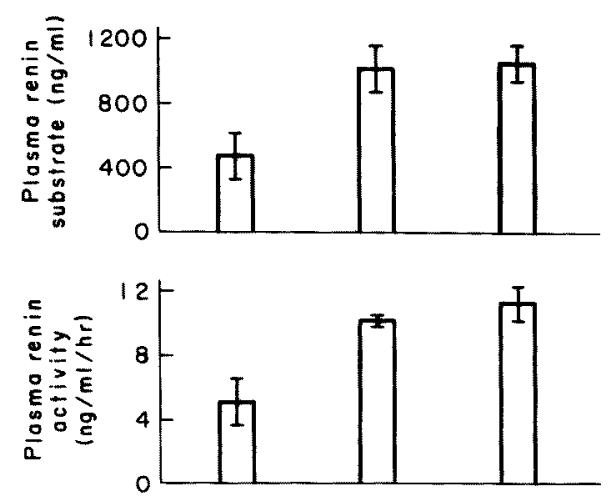

Fig. 1. Plasma renin substrate, activity, and concentration and juxtaglomerular granulation index in estrogen treated normotensive and hyper-

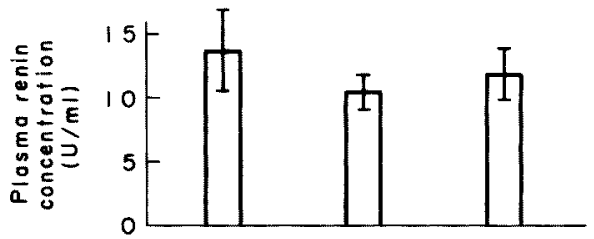
tensive rats. Vertical lines indicate \pm S.D.

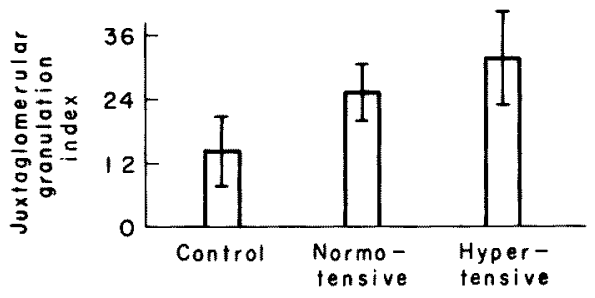

higher than those in the control group $(p<0.01)$. On the other hand, PRC was slightly suppressed in the estrogen treated group, and its suppression was especially remarkable in rats that remained normotensive. But in estrogen treated rats, the differences in PRS, PRA and PRC between hypertensive and normotensive groups were not statistically significant $(p>0.05)$.

Estimations of JG granularity as JGI were used to provide indirect indices of the degree of renin production. Contrary to our expectation, JGI of both the hypertensive and normotensive groups of estrogen treated rats were significantly higher than that of the control group of animals $(p<0.01)$ (Fig. 2). However, like PRC, JGI in the rats which became hypertensive tended to be higher than that in the rats which remained normotensive. But this difference was not statistically significant $(p>0.05)$.

\section{Discussion}

Estrogens cause an increase in PRS (Helmer and Griffith 1952; Nasjletti et al. 1971; Menard and Catt 1973; Saruta et al. 1975). This study also demonstrated that PRS increased significantly in estrogen treated rats, and that this increased PRS was accompanied by increased PRA and slightly suppressed PRC. In similar 


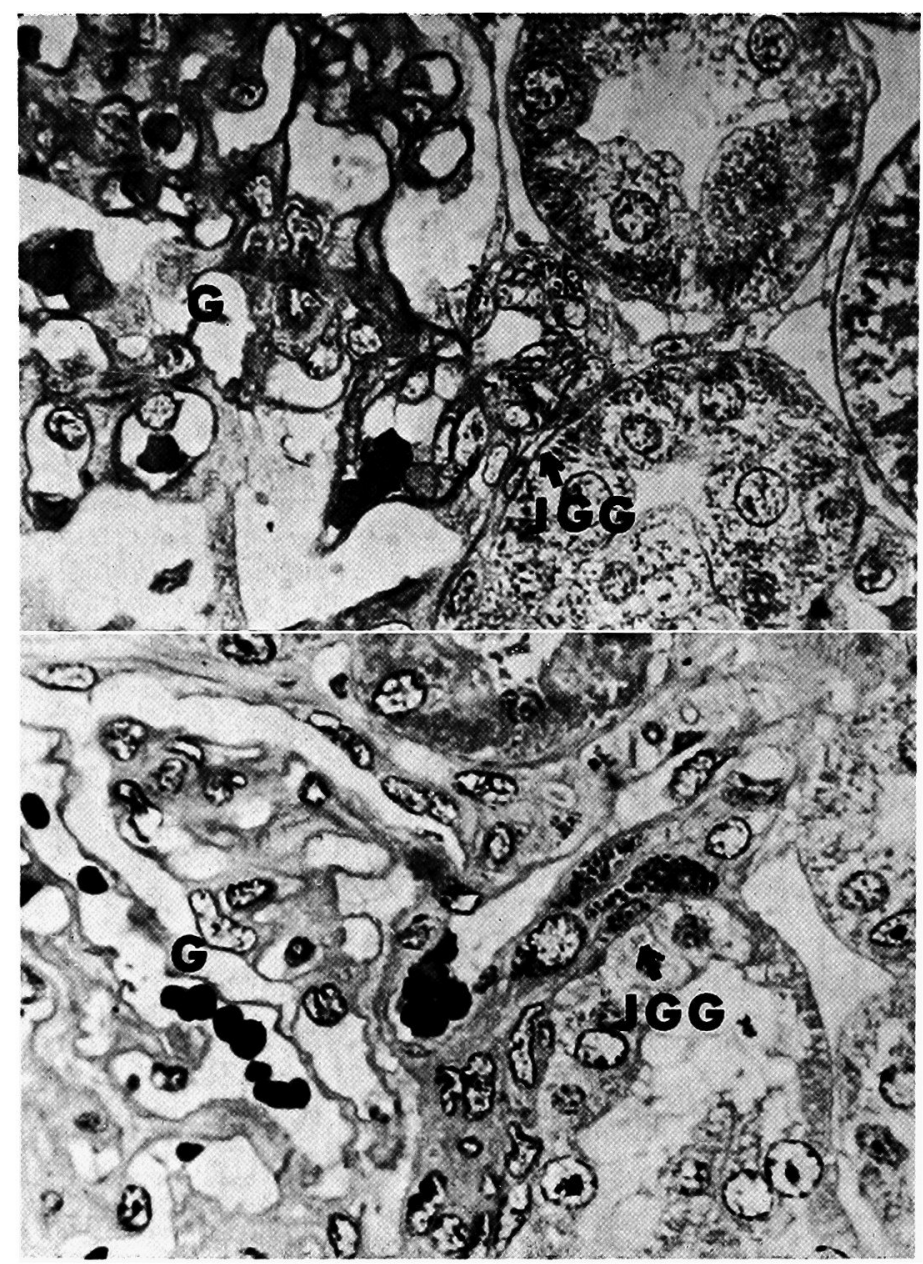

Fig. 2. Hypergranulated juxtaglomerular cells in the rats treated by estrogen. Upper: JGA in a rat which remained normotensive. Lower: JGA in a rat which became hypertensive. G, glomerulus; JGG, juxtaglomerular cell granules. (Bowie stain, $\times 800)$

experiments, Nasjletti et al. (1971) and Menard and Catt (1973) reported that the marked suppression of PRC was induced by the administration of small amounts of estrogen. In this study, we employed much larger amounts of estrogen and found that the suppression of PRC was not so remarkable as seen in their experiments. Therefore, the effect of estrogen upon the renin-angiotensin system seems to be different by the amount of estrogen employed.

Renin is secreted by the JGA in the kidney. In this study JGI was significantly increased in the rats treated by estrogen, although PRC in these rats was slightly suppressed. Since the degree of JG granulation is generally believed to correlate positively with the degree of renin production under a variety of 
subacute and chronic conditions (Hartroft and Hartroft 1961), the observed departure between the PRC and JGI in the present study cannot be easily explained. Newton et al. (1968) previously reported the possibility that estrogens stimulate directly renal production of renin. Slight suppression of PRC and increased JGI in this study might suggest the possibility that the net effect of large amounts of estrogen may represent the resultant balance between a direct trophic influence of the estrogens on the JG cells and the known negative feedback effects on renin secretion of increased angiotensin (Vander and Geelhoed 1965) which is induced by increased PRS.

This study confirmed our previous results that bigh doses of estrogen can increase blood pressure of Wistar male rats (Saruta et al. 1975). However, in the estrogen treated rats, 7 of 24 rats $(29 \%)$ remained normotensive and 7 of 24 rats $(29 \%)$ developed severe hypertension. In the estrogen treated rats the levels of PRS were almost the same in normotensive and hypertensive groups. JGI, PRA and PRC in the rats which developed hypertension by estrogen were a little higher than those in the rats which remained normotensive, but these differences were not statistically significant. Though we previously reported that the increase in blood pressure induced by estrogen was significantly suppressed by salt loading, suggesting the possible role of the renin-angiotensin system in this hypertension, it seems difficult to attribute the development of estrogen hypertension only to this slight changes of the renin components.

Recently McDonald et al. (1977) reported that renin-renin substrate interaction is different in the estrogen treated humans. This renin-renin substrate interaction was reported to be increased in hypertensive patients (Sambhi 1977). These reports might suggest that other factors in addition to quantitative differences in renin and substrate are important in the development of estrogen hypertension.

\section{References}

1) Bowie, D.J. (1935-36) A method for staining the pepsinogen granules in gastric glands. Anat. Rec., 64, 357-367.

2) Hartroft, W.S. \& Hartroft, P.M. (1961) New approaches in the study of cardiovascular disease: aldosterone, renin, hypertension and juxtaglomerular cells. Fed. Proc., 20, 845-854.

3) Helmer, O.M. \& Griffith, R.S. (1952) The effect of the administration of estrogens on the renin-substrate (angiotensinogen) content of rat plasma. Endocrinology, 51, 421426.

4) Laragh, J.H., Sealey, J.E., Ledingham, J.G.G. \& Newton, M.A. (1967) Oral contraceptives. J. Amer. med. Ass., 201, 918-922.

5) Lever, A.F., Robertson, J.I.S. \& Tree, M. (1964) The estimation of renin in plasma by an enzyme kinetic technique. Biochem. J., 91, 346-352.

6) Luft, J.H. (1961) Improvements in epoxy resin embedding methods. J. biophys. biochem. Cytol., 9, 409-414.

7) McDonald, W.J., Cohen, E.L., Lucas, C.P. \& Conn, J.W. (1977) Renin-renin substrate kinetic constants in the plasma of normal and estrogen-treated humans. J. clin. Endocr., 45, 1297-1304.

8) Mayor, H.D., Hampton, J.C. \& Rosario, B. (1961) A simple method for removing the 
resin from epoxy-embedded tissue. J. biophys. biochem. Cytol., 9, 909-910.

9) Menard, J. \& Catt, K.J. (1973) Effects of estrogen treatment on plasma renin parameters in the rat. Endocrinology, 92, 1382-1388.

10) Nasjletti, A., Matsunaga, M., Tateishi, H. \& Masson, G.M.C. (197I) Effects of stilbestrol on the renal pressor system as modified by adrenalectomy and secondary aldosteronism. J. Lab. clin. Med., 78, 30-38.

11) Newton, M.A., Sealey, J.E., Ledingham, J.M. \& Laragh, J.H. (1968) High blood pressure and oral contraceptives. Amer. J. Obstet. Gynec., 101, 1037-1045.

12) Okamoto, K. \& Aoki, K. (1963) Development of a strain of spontaneously hypertensive rats. Jap. Circul. J., 27, 282-293.

13) Sambhi, M.P. (1977) Renin-substrate reaction, an embarkation premise. Circulation Res., 41, Suppl. 2, II-1-II-4.

14) Saruta, T., Saade, G.A. \& Kaplan, N.M. (1970) A possible mechanism for hypertension induced by oral contraceptives. Arch. intern. Med., 127, 621-626.

15) Saruta, T., Nakamura, R., Saito, I., Kondo, K. \& Matsuki, S. (1975) Oestrogen hypertension in rats. Clin. Sci. mol. Med., 48, 457-460.

16) Skinner, S.L. (1967) Improved assay methods for renin concentration and activity in human plasma. Circulat. Res., 20, 391-402.

17) Skinner, S.L., Lumbers, E.R. \& Symonds, E.M. (1969) Alteration by oral contraceptives of normal menstrual changes in plasma renin activity, concentration and substrate. Clin. Sci., 36, 67-76.

18) Vander, A.J. \& Geelhoed, G.W. (1965) Inhibition of renin secretion by angiotensin II. Proc. Sac. exp. Biol. Med. (N.Y.), 120, 399-403. 